\title{
Advantages of dietary, exercise-related, and therapeutic interventions to prevent and treat sarcopenia in adult patients: an update
}

This article was published in the following Dove Press journal:

Clinical Interventions in Aging

31 August 2010

Number of times this article has been viewed

\author{
DL Waters' \\ RN Baumgartner ${ }^{2}$ \\ PJ Garry \\ B Vellas ${ }^{4}$ \\ 'Department of Preventive \\ and Social Medicine, Dunedin \\ School of Medicine, University of \\ Otago, Dunedin, New Zealand; \\ ${ }^{2}$ Department of Epidemiology and \\ Population Health, University of \\ Louisville, Louisville, Kentucky, USA; \\ ${ }^{3}$ Department of Pathology, University \\ of New Mexico School of Medicine, \\ Albuquerque, New Mexico, USA; \\ ${ }^{4}$ Department of Internal Medicine \\ and Geriatric Medicine, University \\ Hospital Center of Toulouse, \\ Gerontopole, Toulouse, France
}

\begin{abstract}
Sarcopenia is the loss of skeletal muscle mass and function with aging. Although the term sarcopenia was first coined in 1989, its etiology is still poorly understood. Moreover, a consensus for defining sarcopenia continues to elude us. Sarcopenic changes in the muscle include losses in muscle fiber quantity and quality, alpha-motor neurons, protein synthesis rates, and anabolic and sex hormone production. Other factors include basal metabolic rate, increased protein dietary requirements, and chronic inflammation secondary to age-related changes in cytokines and oxidative stress. These changes lead to decreased overall physical functioning, increased frailty, falls risk, and ultimately the loss of independent living. Because the intertwining relationships of these factors are complex, effective treatment options are still under investigation. The published data on sarcopenia are vast, and this review is not intended to be exhaustive. The aim of this review is to provide an update on the current knowledge of the definition, etiology, consequences, and current clinical trials that may help address this pressing public health problem for our aging populations.
\end{abstract}

Keywords: aging, muscle loss, nutrition, physical activity

\section{Introduction}

The term sarcopenia first coined by Irwin Rosenberg ${ }^{1}$ in 1989 is now widely accepted to describe the steady and involuntary loss of skeletal muscle mass during aging. Although the word sarcopenia is used in the field of gerontology to describe this phenomenon of aging, the complex multifactorial changes in muscle fiber quantity and quality, protein synthesis rates, alpha-motor neurons of spinal cord, anabolic and sex hormone production are poorly understood. These changes combine and result in a smaller, slower contracting muscle with impaired capacity to generate sufficient strength and power for activities of daily living. ${ }^{2}$ In concert with these multifactorial changes are decreased basal metabolic rate, increased dietary protein needs, and increased exposure to oxidative stress and inflammation. ${ }^{3,4}$ The sum of these changes leads to decreased overall physical functioning and physical activity, increased frailty, falls risk, and fractures, and ultimately to the loss of independent living. The burden of these changes and outcomes related to sarcopenia occurs at both the individual and the societal levels. In 2004, Janssen et $\mathrm{al}^{5}$ estimated that the annual healthcare cost attributable to sarcopenia was approximately $\$ 18$ billion in the United States. In the current environment of global aging, the future health burden of sarcopenia is selfevident, and interventions are needed to slow or reverse the loss of muscle mass and function in our aging populations.
Correspondence: Debra LWaters University of Otago, Department of Preventive and Social Medicine, PO Box 913, Dunedin New Zealand 9054

Tel +6434797222

Fax +6434797298

Email debra.waters@otago.ac.nz 
Challenges to these efforts exist because there is no consensus on an operational definition of sarcopenia, and the development and progression of sarcopenia is a complex process that will require multifaceted approaches. This review summarizes the recent literature on nutrition, physical activity, and therapeutic interventions to prevent or ameliorate sarcopenia. It begins with an overview of how sarcopenia is measured and defined.

\section{Defining sarcopenia}

More precise methods for measuring skeletal muscle mass include dual-energy x-ray absorptiometry (DXA), magnetic resonance imaging, and computed tomography although new technologies such as positron emission tomography and functional magnetic resonance imaging may extend the capability of estimating both "mass" and corresponding "function." However, these measures are costly and not always available outside clinical settings. Bioelectrical impedance analysis (BIA) and anthropometry have also been used, but limitations due to hydration status with BIA and the risk of random and systematic errors while collecting anthropometric measures make these methods less than ideal. Moreover, these methods collect superficial measures such as electrical resistance, skinfold thicknesses, or circumferences that can be used only to indirectly index or predict muscle mass. ${ }^{7}$ Baumgartner et $\mathrm{al}^{8}$ were the first to develop an operational definition of sarcopenia. The approach used sex-specific cutoff values on the statistical distribution of "relative skeletal muscle mass," which was defined as appendicular skeletal muscle mass (ASM) (sum of the masses of arm and leg lean soft tissues from DXA) divided by height squared (also referred to as stature, $\mathrm{ASM} / \mathrm{S}^{2}$ ). The cutoff values for the $\mathrm{ASM} / \mathrm{S}^{2}$ index were defined as -2 standard deviations below the sex-specific means of the distributions in a reference sample of young and middle-aged adults from the Rosetta Study. ${ }^{9}$ Cutoff values of less than $5.45 \mathrm{~kg} / \mathrm{m}^{2}$ for women and $7.26 \mathrm{~kg} / \mathrm{m}^{2}$ for men were applied and shown to identify elders in the New Mexico Aging Process Study who were at increased risk for balance and gait problems, and other correlates of muscle function. The estimated prevalence of sarcopenia in the New Mexico Elder Health Survey increased from $13 \%$ to $24 \%$ in people younger than 70 years to $>50 \%$ in people older than 80 years of age, and was slightly greater in Hispanics than in non-Hispanic whites. ${ }^{8}$ Some subsequent surveys of sarcopenia prevalence in different populations have used these cut scores and arrived at different estimates; however, most of the surveys used different definitions or study populations with different age, racial, and gender characteristics. For example, Melton et $\mathrm{al}^{10}$ proposed cut scores of $6.0 \mathrm{~kg} / \mathrm{m}^{2}$ in women and $8.7 \mathrm{~kg} / \mathrm{m}^{2}$ in men for a sarcopenia index defined as total lean body mass/stature ${ }^{2}$. They derived lower prevalence estimates but their population included people younger than 50 years. Other recent data from Asian countries suggest that higher cut scores are more appropriate for this population. ${ }^{11-13}$ Janssen et a ${ }^{14}$ used receiver operating characteristic curve analysis to estimate optimal cutoff values for predicting disability in a representative US sample (NHANES III) using total skeletal muscle mass (TSM, from BIA) adjusted for stature (TSM/ $\left.\mathrm{S}^{2}\right)$. Cut-off values in the Janssen study for women ranged from 5.76 to $6.75 \mathrm{~kg} / \mathrm{m}^{2}$ and were associated with moderate levels of disability. Less than $5.75 \mathrm{~kg} /$ $\mathrm{m}^{2}$ was associated with high physical disability risk. In men the cut-off values ranged from 8.51 to $10.75 \mathrm{~kg} / \mathrm{m}^{2}$. Interestingly, if these cutoff values are adjusted to approximate ones based on ASM, rather than total muscle mass, they are similar to those originally derived by Baumgartner et al. ${ }^{8}$ Subsequently other investigators have explored a variety of measures including calf muscle circumference, muscle mass as a percent of body weight, the ratio of total lean soft tissue mass to total fat mass, or residuals from a linear regression model. ${ }^{15-17}$ These estimates suggest the original cut scores put forth by Baumgartner from an older New Mexican population may overestimate the prevalence of sarcopenia in some populations and that higher cut scores may be appropriate. In fact, Baumgartner and coworkers ${ }^{18}$ recognized that their initial estimates were too high in a subsequent analysis. To date, no consensus has been reached as to the "best" definition of sarcopenia. Some, in fact, have suggested that the "best" measure should be based on muscle strength rather than on mass particularly in the context of cardiovascular disease risk. ${ }^{19}$

\section{The prevalence of sarcopenia}

Based on the above discussion, it is apparent that the prevalence of sarcopenia in specific populations will vary depending on the methods used to assess muscle mass and the cut scores applied. The prevalence of sarcopenia in the United States and parts of Europe has been reported to be 5\%-13\% in people aged $60-70$ years and $11 \%-50 \%$ in those older than 80 years. ${ }^{17,20-22}$ Sex-specific data in the US data reports that ${ }^{23}$ $53 \%$ males and $43 \%$ females older than the age of 80 were sarcopenic. ${ }^{23}$ Data from Asian countries report the prevalence of sarcopenia to be between $8 \%$ and $22 \%$ for females and between $6 \%$ and $23 \%$ for males. ${ }^{11,12}$ Until a consensus is reached on the standard method to measure skeletal muscle mass and population-specific cut scores, the prevalence of sarcopenia will vary widely across different populations. Nonetheless, a common feature in all studies to date is the 
increasing prevalence of sarcopenia with increasing age. On a global level, increasing longevity combined with low fertility and immigration poses the question whether sarcopenia and its sequel of functional limitations will emerge as a significant public health concern. Moreover, what prevention measures are most effective in slowing or reversing the loss of muscle in later life?

\section{Rate of muscle loss}

It has been established that muscle loss is a significant feature of aging. The rate of muscle loss is estimated to be $1 \%-2 \%$ annually after the age of $50^{24,25}$ in concert with strength declines of $1.5 \%$ per year that accelerates to $3 \%$ annually after the age of $60 .{ }^{18,26,27}$ These losses result in a decrease in total muscle cross-sectional area of about $40 \%$ between 20 and 60 years of age, ${ }^{27}$ and are even higher in sedentary individuals and twice high in men compared with women. ${ }^{26,28}$ Two longitudinal studies investigating age-related, sex-specific losses of skeletal muscle mass reported losses in both sexes, but the loss of fat-free mass occurred at a faster rate in men even after adjusting for free testosterone, insulin-like growth factor-1 (IGF-1), physical activity, and serum albumin. ${ }^{29,30}$ Grip strength also declines with age and has been reported as a predictor of physical functioning and disability. ${ }^{31,32}$ Data from 3 large nationwide

Aging skeletal muscle
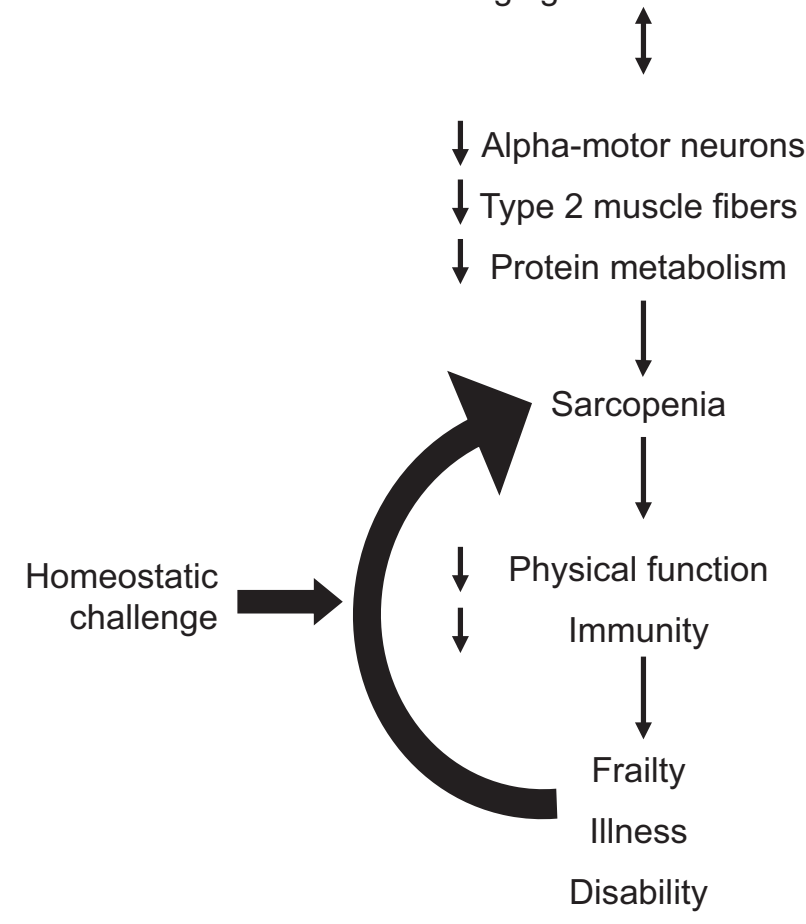

Figure I Proposed downward spiral of muscle loss, frailty and disability. population-based surveys in Denmark (8,342 participants, aged 45-102 years, with up to 4 year follow-up) reported that grip strength declines almost linearly between 50 and 85 years of age. However, among the oldest women, the longitudinal curve reached a horizontal plateau. ${ }^{33}$ Lower health-related quality of life has also been reported in older men and women with lower grip strength and could not be explained by age, size, physical activity, or comorbidity. The investigators proposed that this reflected the link between sarcopenia and generalized frailty. ${ }^{34}$

Accompanying the age-related loss of muscle mass is the increase of fat mass. It is reported that an average adult can expect to gain approximately $0.45 \mathrm{~kg}(1 \mathrm{lb})$ of fat and lose about $0.23 \mathrm{~kg}(0.5 \mathrm{lb})$ of muscle yearly between 30 and 60 years of age. ${ }^{35}$ This shift in body composition is often masked by stable body weight and can result in a body composition phenotype known as sarcopenic obesity. ${ }^{24,28}$ It is more difficult to detect a sarcopenic-obese person as clinical measures of body mass index (BMI) and weight are not sensitive to these shifts in body composition. It is estimated that approximately $30 \%$ of men and $10 \%$ of women older than 80 years have sarcopenic obesity. ${ }^{18,20,26}$ This might explain the discrepancy between Zamboni et $\mathrm{al}^{30}$ who reported significant increases in total body fat $(1.31 \%)$ and percent body fat $(1.27 \%)$ in women but not in men over 2 years (age range 68-78 years at baseline) and Dey et $\mathrm{al}^{29}$ who reported that percent body fat increased only in men $(P<0.05)$ after examining a slightly smaller and older (75-80 years) cohort with a 5-year follow up. This would suggest that there is an interaction between age and sex for body composition changes. More important than the existence of these body composition phenotypes is perhaps their relationship with health and physical function.

\section{Correlates of sarcopenia}

Poor outcomes such as loss of strength, mobility disorders, disability, and poor quality of life have been associated with sarcopenia. ${ }^{36-43}$ Although sarcopenia is the focus of this review, a U-shaped relationship between BMI and functional limitation and disability has been reported. Older adults with BMIs $<18$, who have low muscle and fat mass, have an increased prevalence of function and mobility limitation and disability. Conversely, older obese people with BMIs >30 also have an increased prevalence of functional limitation and disability. ${ }^{20,39}$ The sarcopenic-obese body composition phenotype described above, which cannot be detected by BMI, has also been associated with poorer physical functioning, disability, falls, ${ }^{22,44,46-49}$ and metabolic syndrome. ${ }^{48}$ Some studies suggest 
that sarcopenic obesity may be better for predicting functional consequences than for predicting the loss of skeletal muscle mass alone (pure sarcopenia). ${ }^{40,45,46-49}$ Conversely, others argue that it is the combination of low muscle strength with obesity that is associated with poorer physical function. ${ }^{50,52}$ Still others report that pure obesity is the greater risk factor for functional deficits. ${ }^{53-55}$ Although it is important to address these conflicting data, and as these questions are the subject of ongoing investigations, it is beyond the scope of this review to address these differing views.

Metabolic rate and maximal oxygen consumption $\left(\mathrm{VO}_{2}\right.$ max) also decrease with the loss of muscle mass, ${ }^{25,56,57}$ and this could create higher perceived energy expenditure at lower levels of work output as was reported by Waters et $\mathrm{al}^{58}$ in physically trained sarcopenic adults. The sarcopenic group performed significantly less total work during the resistance exercise and used more energy for less work when compared with nonsarcopenic people matched for self-reported physical activity. If the total work output decreases with sarcopenia, and there is a preferential loss of type 2 muscle fibers and motor neurons, it may result in slower twitch contraction time and maximal shortening speed causing the loss of both muscular strength and power. ${ }^{6}$ Leg power has been associated with functional limitations and is reported to have separate attributes that could influence physical performance. ${ }^{59,60}$ The combined effects of $\mathrm{VO}_{2}$ max and decreasing muscular strength and power most likely contribute to the loss of function during aging. There may also be sex-specific differences as older males apparently rely more on strength and women on coordination when performing the same physical task. ${ }^{61}$ Finally, skeletal muscle is also an important reserve of body protein during the times of malnutrition or stress. ${ }^{62}$ If sarcopenia is particularly severe, it will have the potential not only to reduce resting metabolic rate but also to negatively influence the immune system, thereby reducing the body's ability to respond to homeostatic challenges and create a vicious downward spiral of muscle loss, sarcopenia, frailty, and disability. ${ }^{63-65}$

\section{Muscle protein balance and nutritional intake}

In healthy muscle, proteins and amino acids constantly turn over in equilibrium between protein synthesis and breakdown. ${ }^{66,67}$ This equilibrium is typically disrupted in older people with up to a $30 \%$ lower synthesis rate of mixed muscle proteins including myofibrillar and mitochondrial proteins. ${ }^{67-69}$ It is also been hypothesized that sarcopenia may result from increased rates of protein breakdown under the stimulation of chronic inflammation, ${ }^{64}$ but this is less well established. The evidence in support of this alternative hypothesis will only be briefly discussed.

Muscle protein synthesis is stimulated by dietary intake of both essential and nonessential amino acids, such as leucine and creatine, ${ }^{70-72}$ but it remains unclear how significant decreases in dietary and protein intake influence the development and progression of sarcopenia. Overall, low nutrient intake secondary to the "anorexia of aging" is considered an important risk factor in the development and progression of sarcopenia. ${ }^{18,69,73,74}$ It is also reported that $15 \%$ of those older than 60 years eat less than $75 \%$ of the recommended daily allowance for protein. ${ }^{75}$ Morley ${ }^{69}$ reviewed the phenomena of the anorexia of aging and reported that early satiety, secondary to decreased relaxation of the fundus, increased the release of cholecystokinin in response to fat intake, and that increased leptin levels and neurotransmitters may all play a role in the anorexia of aging. Declining testosterone levels may account for decreasing food intake to a greater extent in men than in women. ${ }^{6,76}$ Thus, although poor overall nutritional intake may play a role in sarcopenia, low protein intake appears to be a significant problem for older adults and may be a potential target for an intervention strategy.

\section{Nutritional interventions}

Daily intake of $1.2-1.5 \mathrm{~g} / \mathrm{kg}$ of protein has been reported to prevent sarcopenia, whereas the current recommended daily dietary protein intake requirement for adults is $0.8 \mathrm{~g} / \mathrm{kg} / \mathrm{d} .^{6}$ Preliminary data from a recent randomized controlled trial indicate that it is more important to ingest a sufficient amount of high-quality protein (25-30 g) with each meal rather than 1 large bolus, because greater than $30 \mathrm{~g}$ in a single meal may not further stimulate muscle protein synthesis. ${ }^{77}$ Furthermore, Paddon-Jones and Rasmussen ${ }^{78}$ reported that aging does not inevitably reduce the anabolic response to a high-quality protein meal, rather it is the presence of carbohydrates that blunts this response due to the effects of insulin resistance on muscle protein synthesis. These data would suggest that highquality protein should be consumed in smaller quantities, but not together with carbohydrates. These recommendations may not be easy to achieve. Volpi et al have conducted a number of experiments investigating muscle protein synthesis and breakdown, and amino acid transport in young and elderly subjects. In 2003, they assessed whether nonessential amino acids are required in a nutritional supplement to stimulate muscle protein anabolism in the elderly and reported that essential amino acids are primarily responsible for the amino acid stimulation of muscle protein anabolism in healthy elderly adults. ${ }^{72}$ 
There is a general agreement that the essential amino acid leucine increases protein anabolism and decreases protein breakdown. ${ }^{78}$ Leucine-rich food sources include legumes such as soybeans and cowpea, and animal products such as beef and fish. Amino acid supplements without adequate leucine reportedly do not stimulate protein synthesis. ${ }^{71,79,80}$ Meat-based products contain higher essential amino acids than vegetable-based and it was suggested by Kim et $\mathrm{al}^{45}$ that older adults should be encouraged to consume a diet higher in lean meat sources or consume essential amino acid supplements particularly if they are engaging in resistance training, as discussed later in this review. The authors are aware of the 3 registered clinical trials currently being conducted to investigate protein nutritional supplements and sarcopenia. These are being conducted at the University of Texas Galveston, Maastricht University Medical Center, and Centre Hospitalier Universitaire de Nice. All are nutritional supplement and resistance training interventions. It is anticipated that these trials and possibly other trials will shed more light on the amount, type, and timing of nutritional supplements either alone or in combination with resistance training to reduce, stabilize, or reverse sarcopenia.

Vitamin D has recently received recognition as another potential intervention strategy for sarcopenia. Older adults are at increased risk of developing vitamin D insufficiency $(<30 \mathrm{ng} / \mathrm{mL})$, and a recent systematic review of vitamin D supplementation reports that supplementation may be indicated in those older people with low vitamin D levels to combat sarcopenia, functional decline, and falls risk. ${ }^{81}$ As people age, skin cannot synthesize vitamin D efficiently and the kidney is less able to convert vitamin $\mathrm{D}$ to its active hormone form. ${ }^{82}$ Salmon, tuna, mackerel, and other fish oils are among the best sources of vitamin D, with small amounts found in beef liver, cheese, and egg yolks. Vitamin D in these foods is primarily in the form of vitamin $\mathrm{D}_{3}$ (cholecalciferol) and its metabolite $25(\mathrm{OH}) \mathrm{D}_{3}{ }^{83}$ People may try to meet their vitamin D needs through exposure to sunlight, ${ }^{84,85}$ but seasons, geographic latitude, time of day, cloud cover, skin melanin content, and sunscreen are among the factors that affect exposure to UV radiation and vitamin D synthesis. ${ }^{86-88}$ Thus, vitamin D supplements are necessary and are available in 2 forms, $\mathrm{D}_{2}$ (ergocalciferol) and $\mathrm{D}_{3}$ (cholecalciferol). Many vitamin $\mathrm{D}$ supplements are being reformulated to contain vitamin $\mathrm{D}_{3}$ instead of vitamin $\mathrm{D}_{2}^{89}$ although both forms (as well as vitamin $\mathrm{D}$ in foods and from cutaneous synthesis) effectively raise serum $25(\mathrm{OH}) \mathrm{D}$ levels. ${ }^{85} \mathrm{~A}$ meta-analysis by Dawson-Hughes ${ }^{81}$ indicated that the evidence for vitamin D supplementation was strong although the dosing, efficacy, and long-term safety of supplementation need to be elucidated. Molecular mechanisms of vitamin D on muscle tissue include the genomic effects that result in changes in gene transcription of messenger RNA and protein synthesis, and the rapid nongenomic effects mediated through the vitamin $\mathrm{D}$ receptor on muscle cells. ${ }^{90}$ Although our understanding of the relationship between vitamin $\mathrm{D}$ and muscle function has advanced over the past decade, a complete understanding of the vitamin $\mathrm{D}$ action on muscle tissue and how this translates into improvements in muscular performance are yet to be elucidated. Currently, there appears to be at least 2 clinical trials investigating vitamin D supplementation: A Pilot Study of the Impact of Vitamin $\mathrm{D}_{3}$ on Muscle Performance in Elderly Women at Tufts University, and the Zurich Disability Prevention Trial at the University of Zurich.

\section{Physical activity}

As has been discussed, the development and progression of sarcopenia are complex and multifactorial. Despite this, there is a growing body of evidence to indicate that physical activity can slow the loss of skeletal muscle and function. Although physical inactivity aggravates the loss of skeletal muscle, highly active older adults continue to lose cardiovascular fitness and muscle mass over time. ${ }^{25,56,57}$ This stresses the importance of the mode of activity in the preservation of lean body mass. A recent 3-year longitudinal study of body composition and physical activity in older adults ${ }^{91}$ reported that body weight remained stable while lean body mass decreased and fat mass increased. This confirmed the earlier studies reporting these shifts in body composition and that these changes cannot be detected by body weight or BMI. ${ }^{24,28}$ Moreover, they found that leisure-time physical activity did not prevent the changes in body composition although higher levels of physical activity were associated with higher muscle mass.

Physical activity encompasses 4 domains: leisure time, occupational, transport, and household. For the purpose of this review we will only focus on leisure-time physical activity and then more specifically resistance training.

\section{Leisure-time physical activity}

In the longitudinal study by Raguso et $a 1,{ }^{91}$ the average time spent in moderate to intense activities reported by the active participants was 90 minutes a day, with approximately $70 \%$ reporting over 60 minutes a day. Examples of moderate-tointense activities in this study were walking up stairs, running, biking, playing tennis, skiing, and swimming. None of the activity included resistance training. Although this level of 
physical activity meets or exceeds the standards recommended by American Heart Association for cardiovascular exercise, ${ }^{92}$ it was not sufficient to maintain lean mass or decrease fat mass. It is a bit surprising that this level of exercise did not positively influence body composition, but highlighted the issues of information bias, particularly social desirability bias, in self-reported physical activity. This is particularly the case for intensity, where people report significantly higher intensity mistaking low levels of exercise intensity for moderate levels of intensity. ${ }^{93}$ Mitchell et $\mathrm{al}^{94}$ also reported similar findings from a large cross-sectional study, where lean muscle mass was not associated with physical activity or dietary intakes. Conversely, others have reported that high levels of physical activity slow the loss of skeletal muscle oxidative capacity and sarcopenia. ${ }^{95,96}$ These conflicting results are likely due to different study designs, activities, and challenges of selfreported physical activity. Moreover, very few studies have included people greater than 80 years of age in whom the prevalence of sarcopenia is highest. It also raises the principle of overload to achieve improvements in strength, power, and hypertrophy in response to resistance training.

\section{Resistance training}

Recent evidence on resistance training supports earlier research that it may be the most effective strategy to combat sarcopenia through muscle hypertrophy and increased muscular strength and power. ${ }^{97-99}$ Until recently, research has focused on the impact of resistance training on muscular strength rather than power, which is the product of force and speed. The decline in muscular power is much steeper than strength and results in a decreased ability to rapidly produce force. ${ }^{100,101}$ As discussed earlier, the loss of muscular power is due to the preferential loss of fast-twitch fibers and motor units, ${ }^{27,43,63,75}$ and has been associated with lower functional status and risk of falling. ${ }^{13,23,46,101-104}$ The following sections will discuss current research on strength and power resistance training targeted to older adults to combat the loss of sarcopenia and functional loss. Table 1 presents the commonly used terminology in resistance training exercise prescription.

\section{Strength training}

There is a growing body of evidence documenting the benefits of strength training for older adults. A systematic review by Latham et $\mathrm{al}^{105}$ reported that most strength training programs had durations of 8-12 weeks, used 2-3 sets of 8-10 repetitions at $65 \%$ of 1 -repetition maximum ( $1 \mathrm{RM})$, and were performed 2-3 days per week. This type of strength training focuses on concentric or shortening muscle contraction and has little influence on eccentric or lengthening muscle strength. ${ }^{106,107}$ Most of the reviewed studies by Latham et al ${ }^{105}$ reported increases in strength, but found limited changes in functional tests such as chair stands and timed up and go. One might assume that resistance training that results in improvements in strength and/or power would also improve physical functioning. A recent Cochran review included 121 trials with 6,700 participants assessing progressive resistance training and physical function. ${ }^{108}$ For the most part, progressive resistance training was performed 2-3 times weekly at a high intensity. The resistance training programs had a large positive effect on muscle strength and a small but significant improvement in physical ability. There was a modest improvement in gait speed and a moderate to large effect for getting out of a chair. These authors concluded that progressive resistance training is an effective intervention for improving strength and physical functioning in older people, including functional performance of some simple and complex tasks. They cautioned that adverse events were not sufficiently reported; thus, transferring these exercises to clinical populations should be approached with caution. Although this review did find a positive relationship between progressive resistance training

Table I Terminology and definitions

\begin{tabular}{ll}
\hline Muscular strength & Amount of force produced for I maximal effort \\
Muscular endurance & Ability of a muscle to contract repeatedly \\
Muscular power & Product of force and speed of movement \\
Exercises & Movements that target specific muscle groups from large muscle groups to isolated muscle movements \\
Repetition & One complete movement of an exercise \\
I repetition maximum (I RM) & Maximal weight that can be lifted for I repetition, safely and with proper form \\
Set & Series of continuous repetitions (eg, I0 repetitions/set) \\
Intensity & Amount of weight lifted specified as either a percentage of I RM (eg, 70\% of I RM) or a specified \\
& number of repetitions within a set \\
Frequency & Number of days per week each exercise session is conducted \\
Duration & Length of time for each exercise session \\
Volume & Sum of frequency, intensity, and duration \\
\hline
\end{tabular}


with strength and function, it did not specifically address the question of power versus strength training.

\section{Power training}

As noted earlier and in association with the greater loss of type 2 muscle fibers, muscular power declines at a faster rate than strength. There is also evidence that muscular power impacts more on physical functioning than strength. ${ }^{97,98,107,109-114}$ Many published studies of power training used 3-4 sets at intensities of $20 \%-80 \%$ of 1 RM, $2-3$ times per week for $8-16$ weeks. All of these studies reported significant improvement in strength and power, with some reporting improved measures of physical functioning. ${ }^{109,112,113,115}$ On one hand, 2 randomized controlled trials comparing strength to power training 98,109 reported similar improvements in strength but greater improvements in power performance. On the other hand, other trials ${ }^{112,114}$ reported similar improvements in both strength and power performance. These data highlight the symbiotic relationship in the physiological response to strength and power training, whereby the response to power training results in gains of both strength and power. Conversely, strength training generally only increases strength but does not improve power unless the speed of contractions is very high. ${ }^{98}$

Several recent investigations have reported that physical function, particularly in the lower limbs, has a stronger relationship with muscular power than strength. ${ }^{60,102,104}$ In order for skeletal muscle to achieve and maintain muscular strength and power, resistance training needs to use a progressively increasing load to maintain the desired range of repetitions per set of exercise. The American College of Sports Medicine recently put forward a position statement on progressive resistance training in healthy adults. ${ }^{92}$ They recommended a $2 \%-10 \%$ increase in load when the individual can perform the current workload for 1-2 repetitions over the desired number. They also recommended that progression in power training uses 2 loading stages: the first stage is strength training and the second stage is light loads $(0 \%-60 \%$ of $1 \mathrm{RM}$ for lower body exercises; $30 \%-60 \%$ of 1 RM for upper body exercises) performed at a fast contraction velocity with 3-5 minutes of rest between sets for multiple sets per exercise ( $3-5$ sets). This is slightly different from intense loading used during power training and reported in the above studies.

\section{Resistance training combined with nutritional interventions}

Although the evidence for resistance training to combat sarcopenia is convincing, Johnston et al ${ }^{116}$ questioned whether this intervention effectively interferes with the processes underlying sarcopenia or only masks the effects. Adults between 65 and 75 years reportedly have a blunted cellular or molecular muscle hypertrophy and protein synthesis response to resistance training compared with younger people. ${ }^{46,117}$ In animal models combining nutritional interventions, such as high-protein or leucine ingestion, with resistance training, anabolic processes appeared enhanced and catabolic pathways were inhibited in older skeletal muscle. ${ }^{118} \mathrm{~A}$ eucaloric diet supplemented with moderately high levels of protein (30 to $>100 \mathrm{~g}$ ) also demonstrated enhanced muscle tissue accumulation and reversed the blunted protein synthesis response to resistance training. ${ }^{19,120}$ Alternatively, a 15 -g bolus of essential amino acids 1 hour after moderately intense resistance training (70\% of $1 \mathrm{RM}$ ) in older participants normalized protein synthesis to a younger pattern of protein synthesis over a period of 5 hours after ingestion. ${ }^{121}$ Recently ornithine alpha-ketoglutarate $(\mathrm{OKG})$, which is a precursor of amino acids such as glutamine and arginine, is receiving attention as a potential nutritional strategy to modulate muscle protein metabolism during aging. ${ }^{122}$

The authors are aware of the 3 clinical trials being conducted across France, Belgium, and the United States to investigate the relationships between protein supplementation and resistance training on muscle protein metabolism in older adults.

\section{Therapeutic interventions}

In addition to nutritional and exercise interventions, other therapeutic modalities have also been used to prevent, delay, or reverse sarcopenia including anabolic hormones such as testosterone, estrogen, and growth hormone (GH); creatine; angiotensin II converting enzyme inhibitors (ACEIs); and antimyostatin agents. Newer agents such as antimyostatin and specific androgen receptor modulators (SARMs) are in early stages of testing for safety and efficacy, whereas the older interventions (ie, testosterone and GH) have position statements regarding their efficacy and safety. These are discussed briefly below.

In males, testosterone decreases by $1 \%$ per year and bioavailable testosterone by $2 \%$ per year from age $30 .^{76,123,124}$ In women, testosterone levels drop rapidly from 20 to 45 years of age. ${ }^{125}$ Currently, testosterone replacement is not recommended for the treatment of sarcopenia due to the high rates of side effects and low benefits to physical performance. ${ }^{126}$ SARMs may hold more promise for anabolic effects on skeletal muscle without the side effects, ${ }^{127}$ but are in the early stages of clinical investigations. 
The release of GH from the pituitary and subsequent IGF-I synthesis decreases with increasing age. This lead to investigations administering recombinant growth hormone $(\mathrm{rGH})$ to older patients either with $\mathrm{rGH}$ alone or in combination with sex steroids or exercise. ${ }^{124,128,129}$ The results of these studies did not support the use of rGH in older nonhypopituitary adults as it did not show efficacy, had high rates of adverse events, and increased the risk of neoplasia. ${ }^{129}$ A statement released by Growth Hormone Research Society in the United States recommended that until carefully designed, long-term studies using validated outcome parameters are conducted, the clinical use of rGH in older adults, alone or in combination with testosterone, cannot be recommended. Similarly, estrogen and tibolone (a synthetic steroid with estrogenic, androgenic, and progestogenic properties) are not recommended until further research is conducted to determine the long-term safety in older adults. ${ }^{130}$

\section{Antioxidants}

Oxidative stress has also been suggested in the etiology of sarcopenia and is influenced by both the increased generation of reactive oxygen species (ROS) and age-associated decreases in antioxidant defense. ${ }^{131}$ Exposure to high levels of ROS is reported to modify mitochondrial DNA, the electron transport system, and result in reduced $\mathrm{Ca}^{2+}$ uptake by the sarcoplasmic reticulum ultimately accelerating ROS production and leading to myofiber death. ${ }^{3,132,133}$ Nonexhaustive exercise stimulates the expression of certain antioxidants through enzymatic pathways and it has been questioned whether exercise training should be supplemented with exogenous antioxidants. ${ }^{131}$ Recently, Fusco et al ${ }^{134}$ wrote a salient review on antioxidant supplementation stressing that a better understanding of oxidation mechanisms, markers of oxidative damage and antioxidant status, and timing of antioxidant supplementation is needed before the widespread use of antioxidant supplementation can be advised or refuted.

Until such time, foods may be a preferred source of antioxidants because they contain a wide array of antioxidant substances and are also high in vitamins, minerals and fiber. Vegetables rich in antioxidants include pinto, red and black beans, and russet potatoes. Fruits include berries such as cranberry, blueberry, blackberry, and raspberry, and also plums, apples, cherries, prunes and pecans. ${ }^{135}$

\section{Creatine}

Dietary creatine is derived primarily from meat $(1 \mathrm{~kg}$ contains $\sim 5 \mathrm{~g}$ of creatine) and is nonenzymatically converted to creatinine. Creatine monohydrate was considered a potential ergogenic aid due to its buffering action against proton accumulation and by the increasing skeletal muscle concentrations of phosphocreatine needed for high-intensity muscular contractions. ${ }^{136}$ Creatine supplementation combined with resistance training has been reported to be effective for increasing strength in older adults. ${ }^{137-139}$ Creatine appears well tolerated in these short-term studies, but there are few data on long-term studies. Because the mechanisms of creatine actions are poorly understood, more long-term trials are needed to determine its safety and efficacy for renal, hepatic, cardiac, and muscle functions.

\section{Angiotensin II converting enzyme inhibitors (ACEls)}

ACEIs works by suppressing the angiotensin - aldosterone system, thereby preventing the formation of angiotensin II that acts as a powerful vasoconstrictor. ${ }^{140}$ Blood pressure is partially regulated by ACEIs. It also reduces the pre- and afterload on the heart improving myocardial contractility. ${ }^{141}$ ACEIs are widely used in treating hypertension and heart failure in older adults, ${ }^{142}$ and 3 cohort studies have reported improved body composition and physical function associated with ACEIs in older adults. ${ }^{143-145}$ A recently completed randomized controlled trial of ACEIs reported improvements in exercise capacity and fewer falls in 130 older participants with existing impairments of activites of daily living (ADLs). ${ }^{146}$ The mechanisms of ACEIs are unclear but have been suggested to involve improved cardiac output and thus improved blood flow to muscle, reduce inflammatory cytokines, improve endothelial function and muscle glucose uptake, and positively modulate the IGF-1 system, all of which have implications for body composition changes. ${ }^{147}$ Because ACEIs have been prescribed since the 1980s to treat hypertension and heart failure in older adults, the long-term safety of ACEIs may already be established. Thus, although the mechanisms for ACEI action on skeletal muscle are yet to be elucidated, it could be a safe and effective means to improve body composition and function in older adults.

\section{Myostatin}

Myostatin is a member of the transforming growth factor-beta superfamily and is known to be a negative regulator of skeletal muscle myogenesis. ${ }^{148,149}$ The primary action of myostatin is the negative regulation of skeletal muscle satellite cell activation, proliferation, and cell self-renewal. ${ }^{150}$ Currently, clinical trials of antimyostatin drugs are confined to animal models and it will be some time before trials are conducted in humans. 


\section{Conclusion}

Although the functional and financial consequences of sarcopenia are significant from a public health perspective, clinical cut scores for specific populations are needed before sarcopenia can be diagnosed and treated. With exception of ACEI as a pharmaceutical intervention, the most compelling evidence to combat sarcopenia is resistance training either alone or in combination with nutritional supplements. Considering the multifactorial nature of the sarcopenic process, comprehensive interventions such as those mentioned above are likely needed. Certainly, the cornerstone interventions of resistance training and nutritional supplements should be considered and adopted when possible. The feasibility, sustainability, and safety of power resistance training in older adults and the influence of nutritional supplementation with power training need to be confirmed by larger longitudinal trials. There are also issues regarding how to implement resistance-training programs into the community- or homebased programs. Community-based programs are gaining popularity, and the feasibility of peer-led strength classes has been reported. ${ }^{151}$ Home-based programs may be an option for frail elderly who are home bound. ${ }^{152,153}$ Finally, pharmacologic approaches under investigation also hold promise for a greater understanding of the mechanisms and potential interventions to combat or reverse sarcopenia.

\section{Disclosure}

The authors report no conflicts of interest in this work.

\section{References}

1. Rosenberg IH. Sarcopenia: origins and clinical relevance. J Nutr. 1997;127 Suppl:S990-S991.

2. Roubenoff R. Sarcopenia: effects on body composition and function. J Gerontol A Biol Sci Med Sci. 2003;58(11):1012-1017.

3. Fulle S, Protasi F, DiTano G, Pietrangelo T, Beltramin A, Boncompagni $\mathrm{S}$. The contribution of reactive oxygen species to sarcopenia and muscle aging. Exp Gerontol. 2004;39:17-24.

4. Wilson M-MG, Morley JE. Invited review: aging and energy balance. J Appl Physiol. 2003;95:1728-1736.

5. Janssen I, Shepard DS, Katzmarzyk PT, Roubenoff R. The healthcare costs of sarcopenia in the United States. J Am Geriatr Soc. 2004;52(1):80-85

6. Morley JE. Sarcopenia: diagnosis and treatment. J Nutr Health Aging. 2008;12(7):452-456.

7. Heymsfield SB, Pietrobelli A, Wang Z, Saris WH. The end of body composition methodology research? Curr Opin Clin Nutr Metab Care. 2005;8(6):591-594.

8. Baumgartner RN, Koehler KM, Gallagher D, et al. Epidemiology of sarcopenia among the elderly in New Mexico. Am J Epidemiol. 1998;147(8):755-763.

9. Mott JW, Wang JC, Thornton DB, Heysfield SB, Pierson Jr RN. Relation between body fat and age in 4 ethnic groups. Am J Clin Nutr. 1999;69:1007-1013.

10. Melton LJ III, Khosla S, Riggs BL. Epidemiology of sarcopenia. Mayo Clin Proc. 2000;75 Suppl:S10-S12.
11. Chien M-Y, Huang T-Y, Wu Y-T. Prevalance of sarcopenia estimated using bioelectrical impedance analysis prediction equation in community-dwelling elderly people in Taiwan. J Am Geriatr Soc. 2008;56:1710-1715.

12. Kim TN, Yang SJ, Yoo HJ, et al. Prevalence of sarcopenia and sarcopenic obesity in Korean adults: the Korean sarcopenic obesity study. Int $J$ Obes (Lond). 2009 Aug;33(8):885-892. Epub 2009 Jun 30.

13. Woo J, Leung J, Sham A, Kwok T. Defining sarcopenia in terms of risk of physical limitations: a 5-year follow-up study of 3,153 chinese men and women. J Am Geriatr Soc. 2009;57(12):2224-2231.

14. Janssen I, Baumgartner RN, Ross R, Rosenberg IH, Roubenoff R. Skeletal muscle cutpoints associated with elevated physical disability risk in older men and women. Am J Epidemiol. 2004;159(4):413-421.

15. Lauretani F, Russo CR, Bandinelli S, et al. Age-associated changes in skeletal muscles and their effect on mobility: an operational diagnosis of sarcopenia. J Appl Physiol. 2003;95(5):1851-1860.

16. Newman AB, Kupelian V, Visser M, et al. Sarcopenia: alternative definitions and associations with lower extremity function. J Am Geriatr Soc. 2003;51(11):1602-1609.

17. Tankó LB, Movsesyan L, Mouritzen U, Christiansen C, Svendsen OL. Appendicular lean tissue mass and the prevalence of sarcopenia among healthy women. Metabolism. 2002;51(1):69-74.

18. Morley JE, Baumgartner RN, Roubenoff R, Mayer J, Nair KS. Sarcopenia. J Lab Clin Med. 2001;137(4):231-243.

19. Stephen WC, Janssen I. Sarcopenic-obesity and cardiovascular disease risk in the elderly. Nutr Health Aging. 2009;13(5):460-466.

20. Baumgartner RN. Body composition in healthy aging. Ann N Y Acad Sci. 2000;904:437-448.

21. Gillette-Guyonnet S, Nourhashemi F, Andrieu S, et al. Body composition in French women 75+ years of age: the EPIDOS study. Mech Ageing Dev. 2003;124(3):311-316.

22. Janssen I, Heymsfield SB, Ross R. Low relative skeletal muscle mass (sarcopenia) in older persons is associated with functional impairment and physical disability. J Am Geriatr Soc. 2002;50(5): 889-896.

23. Taaffe DR, Duret C, Wheeler S, Marcus R. Once-weekly resistance exercise improves muscle strength and neuromuscular performance in older adults. J Am Geriatr Soc. 1999;47(10): 1208-1214.

24. Hughes VA, Frontera WR, Roubenoff R, Evans WJ, Singh MA. Longitudinal changes in body composition in older men and women: role of body weight change and physical activity. Am J Clin Nutr. 2002;76(2):473-481.

25. Sehl ME, Yates FE. Kinetics of human aging: I. Rates of senescence between ages 30 and 70 years in healthy people. J Gerontol A Biol Sci Med Sci. 2001;56(5):B198-B208.

26. Roubenoff R. Sarcopenia and its implications for the elderly. Eur J Clin Nutr. 2000;54 Suppl 3:S40-S47.

27. Vandervoort AA. Aging of the human neuromuscular system. Muscle Nerve. 2002;25(1):17-25.

28. Gallagher D, Ruts E, Visser M, et al. Weight stability masks sarcopenia in elderly men and women. Am J Physiol Endocrinol Metab. 2000;279(2):E366-E375.

29. Dey DK, Bosaeus I, Lissner L, Steen B. Changes in body composition and its relation to muscle strength in 75-year-old men and women: a 5-year prospective follow-up study of the NORA cohort in Göteborg, Sweden. Nutrition. 2009;25(6):613-619.

30. Zamboni M, Zoico E, Scartezzini T, et al. Body composition changes in stable-weight elderly subjects: the effect of sex. Aging Clin Exp Res. 2003;15(4):321-327.

31. Al Snih S, Markides K, Ottenbacher K, Raji M. Hand grip strength and incident ADL disability in elderly Mexican Americans over a seven-year period. Aging Clin Exp Res. 2004;16(6):481-486.

32. Nybo H, Gaist D, Jeune B, McGue M, Vaupel JW, Christensen K. Functional status and self-rated health in 2,262 nonagenarians: the Danish1905 Cohort Survey. J Am Geriatr Soc. 2001;49: 601-609. 
33. Frederiksen H, Hjelmborg J, Mortensen J, McGue M, Vaupel JW, Christensen K. Age trajectories of grip strength: cross-sectional and longitudinal data among 8,342 Danes aged 46 to 102. Ann Epidemiol. 2006;16(7):554-562.

34. Sayer AA, Syddall HE, Martin HJ, Dennison EM, Roberts HC, Cooper C. Is grip strength associated with health-related quality of life? Findings from the Hertfordshire Cohort Study. Age Ageing. 2006;35(4):409-415.

35. Forbes GB. Longitudinal changes in adult fat-free mass: influence of body weight. Am J Clin Nutr. 1999;70(6):1025-1031.

36. Cruz-Jentoft AJ, Landi F, Topinková E, Michel JP. Understanding sarcopenia as a geriatric syndrome. Curr Opin Clin Nutr Metab Care. 2010;13(1):1-7.

37. Reid KF, Naumova EN, Carabello RJ, Phillips EM, Fielding RA. Lower extremity muscle mass predicts functional performance in mobilitylimited elders. J Nutr Health Aging. 2008;12(7):493-498.

38. Williams MA, Stewart KJ. Impact of strength and resistance training on cardiovascular disease risk factors and outcomes in older adults. Clin Geriatr Med. 2009;25(4):703-714.

39. Zoico E, Di Francesco V, Guralnik JM, et al. Physical disability and muscular strength in relation to obesity and different body composition indexes in a sample of healthy elderly women. Int J Obes Relat Metab Disord. 2004;28(2):234-241.

40. Delmonico MJ, Harris TB, Lee JS, et al. Alternative definitions of sarcopenia, lower extremity performance, and functional impairment with aging in older men and women. J Am Geriatr Soc. 2007;55(5): 769-774.

41. Lang T, Streeper T, Cawthon P, Baldwin K, Taaffe DR, Harris TB. Sarcopenia: etiology, clinical consequences, intervention, and assessment. Osteoporos Int. 2010;21(4):543-599.

42. Lloyd BD, Williamson DA, Singh NA, et al. Recurrent and injurious falls in the year following hip fracture: a prospective study of incidence and risk factors from the Sarcopenia and Hip Fracture Study. J Gerontol A Biol Sci Med Sci. 2009;64(5):599-609.

43. Marcell TJ. Sarcopenia: causes, consequences, and preventions. $J$ Gerontol A Biol Sci Med Sci. 2003;58(10):M911-M916.

44. Waters DL, Hale L, Grant AM, Herbison P, Goulding A. Osteoporosis and gait and balance disturbances in older sarcopenic obese New Zealanders. Osteoporos Int. 2010;21(2):351-357.

45. Kim JS, Wilson JM, Lee SR. Dietary implications on mechanisms of sarcopenia: roles of protein, amino acids and antioxidants. $J$ Nutr Biochem. 2010;21(1):1-13.

46. Baumgartner RN, Waters DL. Sarcopenia and sarcopenic-obesity. In: Pathy MSJ, editor. Principles and Practice of Geriatric Medicine. Vol 2. UK: John Wiley and Sons Ltd; 2006:909-933.

47. Baumgartner RN, Wayne SJ, Waters DL, Janssen I, Gallagher D, Morley JE. Sarcopenic obesity predicts instrumental activities of daily living disability in the elderly. Obes Res. 2004;12(12):1995-2004.

48. Jarosz PA, Bellar A. Sarcopenic obesity: an emerging cause of frailty in older adults. Geriatr Nurs. 2009;30(1):64-70.

49. RollandY, Lauwers-Cances V, Cristini C, et al. Difficulties with physical function associated with obesity, sarcopenia, and sarcopenic-obesity in community-dwelling elderly women: the EPIDOS (EPIDemiologie de l'OSteoporose) Study. Am J Clin Nutr. 2009;89(6):1895-1900.

50. Bouchard DR, Janssen I. Dynapenic-obesity and physical function in older adults. J Gerontol A Biol Sci Med Sci. 2010;65(1):71-77.

51. Stenholm S, Alley D, Bandinelli S, et al. The effect of obesity combined with low muscle strength on decline in mobility in older persons: results from the InCHIANTI study. Int J Obes (Lond). 2009;33(6):635-644.

52. Bouchard DR, Beliaeff S, Dionne IJ, Brochu M. Fat mass but not fat-free mass is related to physical capacity in well-functioning older individuals: nutrition as a determinant of successful aging (NuAge) - the Quebec Longitudinal Study. J Gerontol A Biol Sci Med Sci. 2007;62(12):1382-1388.

53. Ramsay SE, Whincup PH, Shaper AG, Wannamethee SG. The relations of body composition and adiposity measures to ill health and physical disability in elderly men. Am J Epidemiol. 2006;164(5):459-469.
54. Sternfeld B, Ngo L, Satariano WA, Tager IB. Associations of body composition with physical performance and self-reported functional limitation in elderly men and women. Am J Epidemiol. 2002;156(2):110-121.

55. Visser M, Deeg DJ, Lips P, Harris TB, Bouter LM. Skeletal muscle mass and muscle strength in relation to lower-extremity performance in older men and women. $J$ Am Geriatr Soc. 2000;48(4): 381-386.

56. Hawkins SA, Marcell TJ, Victoria Jaque S, Wiswell RA. A longitudinal assessment of change in $\mathrm{VO}_{2} \max$ and maximal heart rate in master athletes. Med Sci Sports Exerc. 2001;33(10):1744-1750.

57. van Pelt RE, Dinneno FA, Seals DR, Jones PP. Age-related decline in RMR in physically active men: relation to exercise volume and energy intake. Am J Physiol Endocrinol Metab. 2001;281(3): E633-E639.

58. Waters DL, Mullins PG, Qualls CR, Raj DS, Gasparovic C, Baumgartner RN. Mitochondrial function in physically active elders with sarcopenia. Mech Ageing Dev. 2009;130(5):315-319.

59. Bean JF, Kiely DK, LaRose S, Alian J, Frontera WR. Is stair climb power a clinically relevant measure of leg power impairments in at-risk older adults? Arch Phys Med Rehabil. 2007;88(5):604-609.

60. Puthoff ML, Nielsen DH. Relationships among impairments in lowerextremity strength and power, functional limitations, and disability in older adults. Phys Ther. 2007 Oct;87(10):1334-1347. Epub 2007 Aug 7.

61. Singh AS, Chin A, Paw MJ, Bosscher RJ, van Mechelen W. Cross-sectional relationship between physical fitness components and functional performance in older persons living in long-term care facilities. BMC Geriatr. 2006;6:4.

62. Solerte SB, Gazzaruso C, Bonacasa R, et al. Nutritional supplements with oral amino acid mixtures increases whole-body lean mass and insulin sensitivity in elderly subjects with sarcopenia. Am J Cardiol. 2008;101(11A):E69-E77.

63. Doherty TJ. Invited review: aging and sarcopenia. J Appl Physiol. 2003;95(4):1717-1727.

64. Roubenoff R. Physical activity, inflammation, and muscle loss. Nutr Rev. 2007;65(12 Pt 2):S208-S212.

65. Walston J, Hadley E, Ferrucci L, et al. Research agenda for frailty in older adults: toward a better understanding of physiology and etiology: summary from the American Geriatrics Society/National Institute on Aging Research Conference on Frailty in Older Adults. J Am Geriatr Soc. 2006;54(6):991-1001.

66. Short KR, Nair KS. Muscle protein metabolism and the sarcopenia of aging. Int J Sport Nutr Exerc Metab. 2001;11 Suppl:S119-S127.

67. Volpi E, Rasmussen BB. Nutrition and muscle protein metabolism in the elderly. Diabetes Nutr Metab. 2000;13(2):99-107.

68. Hasten DL, Pak-Loduca J, Obert KA, Yarasheski KE. Resistance exercise acutely increases $\mathrm{MHC}$ and mixed muscle protein synthesis rates in 78-84 and 23-32 yr olds. Am J Physiol Endocrinol Metab. 2000;278(4):E620-E626.

69. Morley JE. Anorexia, sarcopenia, and aging. Nutrition. 2001;17(7-8): 660-663.

70. Mann GE, Yudilevich DL, Sobrevia L. Regulation of amino acid and glucose transporters in endothelial and smooth muscle cells. Physiol Rev. 2003;83(1):183-252.

71. Rieu I, Balage M, Sornet C, et al. Increased availability of leucine with leucine-rich whey proteins improves postprandial muscle protein synthesis in aging rats. Nutrition. 2007;23(4):323-331.

72. Volpi E, Kobayashi H, Sheffield-Moore M, Mittendorfer B, Wolfe RR. Essential amino acids are primarily responsible for the amino acid stimulation of muscle protein anabolism in healthy elderly adults. $\mathrm{Am}$ J Clin Nutr. 2003;78(2):250-258.

73. Morley JE. Food for thought. Am J Clin Nutr. 2001;74(5):567-568.

74. Morley JE. Decreased food intake with aging. J Gerontol A Biol Sci Med Sci. 2001;56(2):81-88.

75. Roubenoff R. Sarcopenia: a major modifiable cause of frailty in the elderly. J Nutr Health Aging. 2000;4(3):140-142. 
76. Feldman HA, Longcope C, Derby CA, et al. Age trends in the level of serum testosterone and other hormones in middle-aged men: longitudinal results from the Massachusetts male aging study. J Clin Endocrinol Metab. 2002;87(2):589-598.

77. Symons TB, Sheffield-Moore M, Wolfe RR, Paddon-Jones D. A moderate serving of high-quality protein maximally stimulates skeletal muscle protein synthesis in young and elderly subjects. J Am Diet Assoc. 2009;109(9):1582-1586.

78. Paddon-Jones D, Rasmussen BB. Dietary protein recommendations and the prevention of sarcopenia. Curr Opin Clin Nutr Metab Care. 2009;12(1):86-90.

79. Hayes A, Cribb PJ. Effect of whey protein isolate on strength, body composition and muscle hypertrophy during resistance training. Curr Opin Clin Nutr Metab Care. 2008;11(1):40-44.

80. Katsanos CS, Kobayashi H, Sheffield-Moore M, Aarsland A, Wolfe RR. Aging is associated with diminished accretion of muscle proteins after the ingestion of a small bolus of essential amino acids. Am J Clin Nutr. 2005;82(5):1065-1073.

81. Dawson-Hughes B. Serum 25-hydroxyvitamin D and functional outcomes in the elderly. Am J Clin Nutr. 2008;88(2):S537-S540.

82. Need AG, Morris HA, Horowitz M, Nordin C. Effects of skin thickness, age, body fat, and sunlight on serum 25-hydroxyvitamin D. Am J Clin Nutr. 1993;58:882-885.

83. Ovesen L, Brot C, Jakobsen J. Food contents and biological activity of 25-hydroxyvitamin D: a vitamin D metabolite to be reckoned with? Ann Nutr Metab. 2003;47:107-113.

84. Byrdwell WC, DeVries J, Exler J, Harnly JM, Holden JM, Holick MF. Analyzing vitamin D in foods and supplements: methodologic challenges. Am J Clin Nutr. 2008;88:S554-S557.

85. Cranney C, Horsely T, O’Donnell S, Weiler H, Ooi D, Atkinson S. Effectiveness and Safety of Vitamin D. Rockville, MD: University of Ottawa Evidence-based Practice Center 2007. AHRQ Publication No. 07-E013.

86. Holick MF. Vitamin D: the underappreciated D-lightful hormone that is important for skeletal and cellular health. Curr Opin Endocrinol Diabetes. 2002;9:87-98.

87. Holick MF. Photobiology of vitamin D. In: Feldman D, Pike JW, Glorieux FH, editors. Vitamin D. Vol 1. 2nd ed. Burlington, MA: Elsevier; 2005.

88. Wolpowitz D, Gilchrest BA. The vitamin D questions: how much do you need and how should you get it? J Am Acad Dermatol. 2006;54: 301-317.

89. Houghton LA, Vieth R. The case against ergocalciferol (vitamin D2) as a vitamin supplement. Am J Clin Nutr. 2006;84:694-697.

90. Ceglia L. Vitamin D and skeletal muscle tissue and function. Mol Aspects Med. 2008;29(6):407-414.

91. Raguso CA, Kyle U, Kossovsky MP, et al. A 3-year longitudinal study on body composition changes in the elderly: role of physical exercise. Clin Nutr. 2006;25:573-580.

92. Nelson M, Rejeski J, Blair S, et al. Physical activity and public health in older adults. Recommendation from the American College of Sports Medicine and theAmerican Heart Association. Circulation. 2007;116:1094-1105.

93. McLean G, Tobias M. The New Zealand Physical Activity Questionnaire: Report on the Validation of the NZPAQ-Long and NZPAQ-Short Form Physical Activity Questionnaires. Wellington, New Zealand: SPARC; 2004.

94. Mitchell D, Haan MN, Steinberg FM, Visser M. Body composition in the elderly: the influence of nutritional factors and physical activity. J Nutr Health Aging. 2003;7(3):130-139.

95. Hughes VA, Roubenoff R, Wood M, Frontera WR, Evans WJ, Fiatarone Singh MA. Anthropometric assessment of 10-y changes in body composition in the elderly. Am J Clin Nutr. 2004;80(2): 475-482.

96. Kent-Braun JA, Ng AV. Skeletal muscle oxidative capacity in young and older women and men. J Appl Physiol. 2000;89(3): 1072-1078.
97. de Vos NJ, Singh NA, Ross DA, Stavrinos TM, Orr R, Fiatarone Singh MA. Effect of power-training intensity on the contribution of force and velocity to peak power in older adults. J Aging Phys Act. 2008;16(4):393-407.

98. Fielding RA, LeBrasseur NK, Cuoco A, Bean J, Mizer K, Fiatarone Singh MA. High-velocity resistance training increases skeletal muscle peak power in older women. J Am Geriatr Soc. 2002;50(4):655-662.

99. Miszko TA, Cress ME, Slade JM, et al. Effect of strength and power training on physical function in community-dwelling older adults. J Gerontol A Biol Sci Med Sci. 2003;58(2): $171-175$

100. Macaluso A, De Vito G. Muscle strength, power and adaptations to resistance training in older people. Eur J Appl Physiol. 2004;91(4): $450-472$.

101. Perry MC, Carville SF, Smith IC, Rutherford OM, Newham DJ. Strength, power output and symmetry of leg muscles: effect of age and history of falling. Eur J Appl Physiol. 2007;100(5):553-561. Epub 2006 Jul 18.

102. Bean JF, Leveille SG, Kiely DK, Bandinelli S, Guralnik JM, Ferrucci LJ. A comparison of leg power and leg strength within the InCHIANTI study: which influences mobility more? Gerontol A Biol Sci Med Sci. 2003;58(8):728-733

103. Foldvari M, Clark M, Laviolette LC, et al. Association of muscle power with functional status in community-dwelling elderly women. J Gerontol A Biol Sci Med Sci. 2000;55(4):M192-M199.

104. Suzuki T, Bean JF, Fielding RA. Muscle power of the ankle flexors predicts functional performance in community-dwelling older women. J Am Geriatr Soc. 2001;49(9):1161-1167.

105. Latham NK, Bennett DA, Stretton CM, Anderson CS. Systematic review of progressive resistance strength training in older adults. J Gerontol A Biol Sci Med Sci. 2004;59(1):48-61.

106. Reeves ND, Maganaris CN, Longo S, Narici MV. Differential adaptations to eccentric versus conventional resistance training in older humans. Exp Physiol. 2009;94(7):825-833.

107. Sayers SP. High-speed power training: a novel approach to resistance training in older men and women. A brief review and pilot study. J Strength Cond Res. 2007;21(2):518-526.

108. Liu CJ, Latham NK. Progressive resistance strength training for improving physical function in older adults. Cochrane Database Syst Rev. 2009;(3):CD002759.

109. Bottaro M, Machado SN, Nogueira W, Scales R, Veloso J. Effect of high versus low-velocity resistance training on muscular fitness and functional performance in older men. Eur J Appl Physiol. 2007;99(3): 257-264.

110. Calvo MS, Whiting SJ, Barton CN. Vitamin D fortification in the United States and Canada: current status and data needs. Am J Clin Nutr. 2004;80:S1710-S1716.

111. Caserotti P, Aagaard P, Larsen JB, Puggaard L. Explosive heavy-resistance training in old and very old adults: changes in rapid muscle force, strength and power. Scand J Med Sci Sports. 2008;18(6): 773-782.

112. Henwood TR, Riek S, Taaffe DR. Strength versus muscle powerspecific resistance training in community-dwelling older adults. J Gerontol A Biol Sci Med Sci. 2008;63(1):83-91.

113. Orr R, Raymond J, Fiatarone Singh M. Efficacy of progressive resistance training on balance performance in older adults: a systematic review of randomized controlled trials. Sports Med. 2008;38(4): 317-343.

114. Reid KF, Callahan DM, Carabello RJ, Phillips EM, Frontera WR, Fielding RA. Lower extremity power training in elderly subjects with mobility limitations: a randomized controlled trial. Aging Clin Exp Res. 2008;20(4):337-343.

115. Henwood TR, Taaffe DR. Improved physical performance in older adults undertaking a short-term programme of high-velocity resistance training. Gerontology. 2005;51(2):108-115.

116. Johnston AP, De Lisio M, Parise G. Resistance training, sarcopenia, and the mitochondrial theory of aging. Appl Physiol Nutr Metab. 2008;33(1):191-199. 
117. Funai K, Parkington JD, Carambula S, Fielding RA. Age-associated decrease in contraction-induced activation of downstream targets of Akt/mTor signaling in skeletal muscle. Am J Physiol Regul Integr Comp Physiol. 2006;290(4):R1080-R1086.

118. Han B, Tong J, Zhu MJ, Ma C, Du M. Insulin-like growth factor-1 (IGF-1) and leucine activate pig myogenic satellite cells through mammalian target of rapamycin (mTOR) pathway. Mol Reprod Dev. 2008;75(5):810-817.

119. Bos C, Benamouzig R, Bruhat A, et al. Short-term protein and energy supplementation activates nitrogen kinetics and accretion in poorly nourished elderly subjects. Am J Clin Nutr. 2000;71(5):1129-1137.

120. Walrand S, Short KR, Bigelow ML, Sweatt AJ, Hutson SM, Nair KS. Functional impact of high protein intake on healthy elderly people. Am J Physiol Endocrinol Metab. 2008;295(4):E921-E928. Epub 2008 Aug 12.

121. Drummond MJ, Dreyer HC, Pennings B, et al. Skeletal muscle protein anabolic response to resistance exercise and essential amino acids is delayed with aging. J Appl Physiol. 2008;104(5):1452-1461. Epub 2008 Mar 6.

122. Walrand S. Ornithine alpha-ketoglutarate: could it be a new therapeutic option for sarcopenia? J Nutr Health Aging. 2010. In press.

123. Morley JE, Kaiser FE, Perry HM III, et al. Longitudinal changes in testosterone, luteinizing hormone, and follicle-stimulating hormone in healthy older men. Metabolism. 1997;46(4):410-413.

124. Sattler FR, Castaneda-Sceppa C, Binder EF, et al. Testosterone and growth hormone improve body composition and muscle performance in older men. J Clin Endocrinol Metab. 2009;94(6):1991-2001.

125. Morley JE, Perry HM III. Androgens and women at the menopause and beyond. J Gerontol A Biol Sci Med Sci. 2003;58(5):M409-M416.

126. Bhasin S, Buckwalter JG. Testosterone supplementation in older men: a rational idea whose time has not yet come. J Androl. 2001;22(5):718-731.

127. Li JJ, Sutton JC, Nirschl A, et al. Discovery of potent and muscle selective androgen receptor modulators through scaffold modifications. J Med Chem. 2007;50(13):3015-3025.

128. Blackman MR, Sorkin JD, Münzer T, et al. Growth hormone and sex steroid administration in healthy aged women and men: a randomized controlled trial. JAMA. 2002;288(18):2282-2292.

129. Sherlock M, Toogood AA. Aging and the growth hormone/insulin like growth factor-I axis. Pituitary. 2007;10(2):189-203.

130. Rolland Y, Czerwinski S, Abellan Van Kan G, et al. Sarcopenia: its assessment, etiology, pathogenesis, consequences and future perspectives. J Nutr Health Aging. 2008;12(7):433-450.

131. Ji LL. Exercise-induced modulation of antioxidant defense. Ann NY Acad Sci. 2002;959:82-92.

132. Dirks A, Leeuwenburgh C. Apoptosis in skeletal muscle with aging. Am J Physiol Regul Integr Comp Physiol. 2002;282:R519-R527.

133. Reid M, Li Y. Cytokines and oxidative signaling in skeletal muscle. Acta Physiol Scand. 2001;171:225-232.

134. Fusco D, Colloca G, Lo Monaco MR, Cesari M. Effects of antioxidant supplementation on the aging process. Clin Interv Aging. 2007;2(3):377-387.

135. Halvorsen BL, Holte K, Myhrstad MC, et al. A systematic screening of total antioxidants in dietary plants. J Nutr. 2002;132:461-471.

136. Tarnopolsky MA, Safdar A. The potential benefits of creatine and conjugated linoleic acid as adjuncts to resistance training in older adults. Appl Physiol Nutr Metab. 2008;33(1):213-227.
137. Brose A, Parise G, Tarnopolsky MA. Creatine supplementation enhances isometric strength and body composition improvements following strength exercise training in older adults. J Gerontol A Biol Sci Med Sci. 2003;58(1):11-19.

138. Chrusch MJ, Chilibeck PD, Chad KE, Davison KS, Burke DG. Creatine supplementation combined with resistance training in older men. Med Sci Sports Exerc. 2001;33(12):2111-2117.

139. Gotshalk LA, Volek JS, Staron RS, Denegar CR, Hagerman FC, Kraemer WJ. Creatine supplementation improves muscular performance in older men. Med Sci Sports Exerc. 2002;34(3):537-543.

140. IsrailiZ. Clinical pharmacokinetics of angiotensin II (AT1) receptor blockers in hypertension. J Hum Hypertens. 2000;14 Suppl 1:S73-S86.

141. Sumukadas D, Witham MD, Struthers AD, McMurdo ME. Ace inhibitors as a therapy for sarcopenia - evidence and possible mechanisms. $J$ Nutr Health Aging. 2008;12(7):480-485.

142. Grady KL. Management of heart failure in older adults. J Cardiovasc Nurs. 2006;21(5 Suppl 1):S10-S14.

143. Di Bari M, van de Poll-Franse LV, Onder G, et al. Antihypertensive medications and differences in muscle mass in older persons: the Health, Aging and Body Composition Study. J Am Geriatr Soc. 2004;52(6):961-966.

144. Onder G, Penninx BW, Balkrishnan R, et al. Relation between use of angiotensin-converting enzyme inhibitors and muscle strength and physical function in older women: an observational study. Lancet. 2002;359(9310):926-930.

145. Strazzullo P, Lacone R, Lacoviello L, et al. Genetic variation in the renin-angiotensin system and abdominal adiposity in men: the Olivetti Prospective Heart Study. Ann Intern Med. 2003;138(1):17-23.

146. Sumukadas D, Witham MD, Struthers AD, McMurdo ME. Effect of perindopril on physical function in elderly people with functional impairment: a randomized controlled trial. CMAJ. 2007;177(8):867-874

147. Witham MD, Sumukadas D, McMurdo ME. ACE inhibitors for sarcopenia - as good as exercise training? Age Ageing. 2008;37(4): 363-365.

148. Langley B, Thomas M, Bishop A, Sharma M, Gilmour S, Kambadur R. Myostatin inhibits myoblast differentiation by down-regulating MyoD expression. J Biol Chem. 2002;277(51): 49831-49840. Epub 2002 Sep 18.

149. Thomas M, Langley B, Berry C, et al. Myostatin, a negative regulator of muscle growth, functions by inhibiting myoblast proliferation. $J$ Biol Chem. 2000;275(51):40235-40243.

150. McCroskery S, Thomas M, Maxwell L, Sharma M, Kambadur R. Myostatin negatively regulates satellite cell activation and self-renewal. J Cell Biol. 2003;162(6):1135-1147.

151. Layne JE, Sampson SE, Mallio CJ, et al. Successful dissemination of a community-based strength training program for older adults by peer and professional leaders: the people exercising program. JAm Geriatr Soc. 2008;56(12):2323-2329.

152. Gardner MM, Buchner DM, Robertson MC, Campbell AJ. Practical implementation of an exercise-based falls prevention programme. Age Ageing. 2001;30(1):77-83.

153. Robertson MC, Devlin N, Gardner MM, Campbell AJ. Effectiveness and economic evaluation of a nurse delivered home exercise programme to prevent falls. 1: Randomised controlled trial. BMJ. 2001;322(7288):697-701.
Clinical Interventions in Aging

\section{Publish your work in this journal}

Clinical Interventions in Aging is an international, peer-reviewed journal focusing on evidence-based reports on the value or lack thereof of treatments intended to prevent or delay the onset of maladaptive correlates of aging in human beings. This journal is indexed on PubMed Central, MedLine, the American Chemical Society's 'Chemical

\section{Dovepress}

Abstracts Service' (CAS), Scopus and the Elsevier Bibliographic databases. The manuscript management system is completely online and includes a very quick and fair peer-review system, which is all easy to use. Visit http://www.dovepress.com/testimonials.php to read real quotes from published authors. 